\title{
Subcutaneous Emphysema in Pregnancy
}

\author{
Shrestha $A^{1}$, Acharya $S^{1}$ \\ Department of General Practice and Emergency Medicine, \\ Patan Academy of Health Science, Patan
}

\section{ABSTRACT}

Spontaneous pneumomediastinum and subcutaneous emphysema are rare complications of labor, especially in the late pregnancy period, but they are usually self-limiting. Management includes avoidance of exacerbative factors and close observation with supportive treatment.

A 19-year-old primi gravida at 36 weeks pregnancy presented with swelling over the right side of the face, neck and chest. Her general examination was normal. Systemic examination revealed swelling with palpatory crepitation over the right side of chest, neck and face, and other examination findings were normal. Chest $\mathrm{X}$-ray revealed subcutaneous emphysema without pneumothorax. The patient left hospital against medical advice.

Keywords: Pregnancy, subcutaneous emphysema, pneumomediastinum

\section{INTRODUCTION}

Pneumomediastinum and associated subcutaneous emphysema in pregnancy are rare complications of pregnancy and labor. The estimated incidences are between $1: 2000$ and 1:10000. Approximately 200 cases of subcutaneous emphysema and pneumomediastinum in labor and delivery have been reported in the literature. ${ }^{1}$ In 1927 Gordon reviewed 130 cases of pneumomediastinum during pregnancy and found that this clinical entity was first referred to in 1618 by Louise Bourgeois, a midwife in France. ${ }^{2}$ In 1784 Simon reported the first case of pneumomediastinum complicating pregnancy. This condition was however first described by Hamman in 1945 and bears his name. ${ }^{3}$ We herein present a case report of subcutaneous emphysema during the third trimester of pregnancy.

\section{CASE REPORT}

A 19-year-old primigravida at 36 weeks pregnancy, from Western Nepal, presented to the emergency room with the chief complaints of cough since three days and swelling of right side of the chest, neck and face since the last two days. The patient gave a history of productive cough with yellowish sputum, which was more severe at night and not associated with fever or shortness of breath. It was followed by swelling of the right side of chest from the next day of cough. Swelling gradually increased, involving the neck and the right side of the neck. However, she gave no history of hemoptysis.

Her bowel habit was normal. She had occasional burning micturition. She did not have any significant medical or surgical history. She was a non-smoker and never took alcohol. There was no history of allergy to any food or drug. She was having regular antenatal check ups at a local health post. She was taking iron tablets and had also taken tetanus toxoid as per schedule. The patient also said that she had had an ultrasound which was

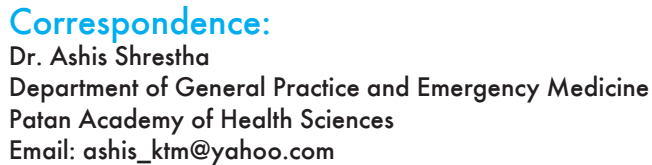


normal. She did not have the ultrasound report when she presented to the emergency room.

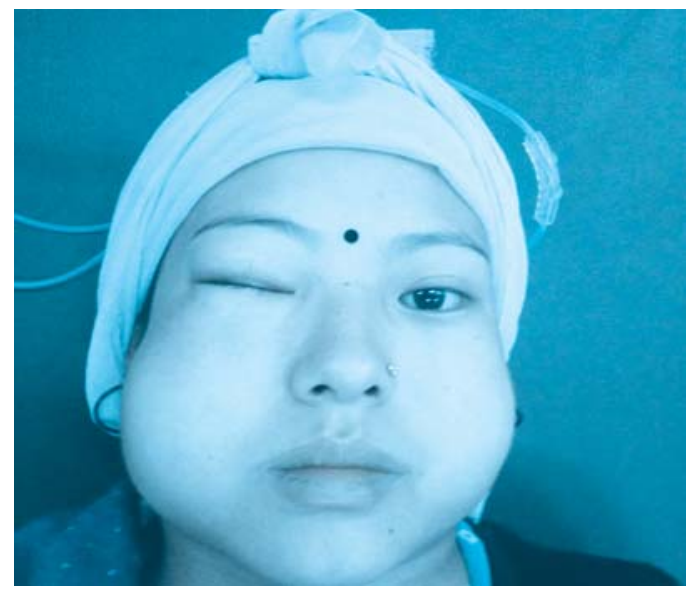

Figure 1. Swelling of the right side of the face

The patient came walking comfortably to the emergency room and her vital signs were normal. There was swelling over the right side of chest extending through the neck to the right side of the face (Figure 1). The swelling was non-tender, crackling in palpation and without increase in local temperature. On auscultation of the chest, air entry was equal on both sides. Other systemic examinations were normal.

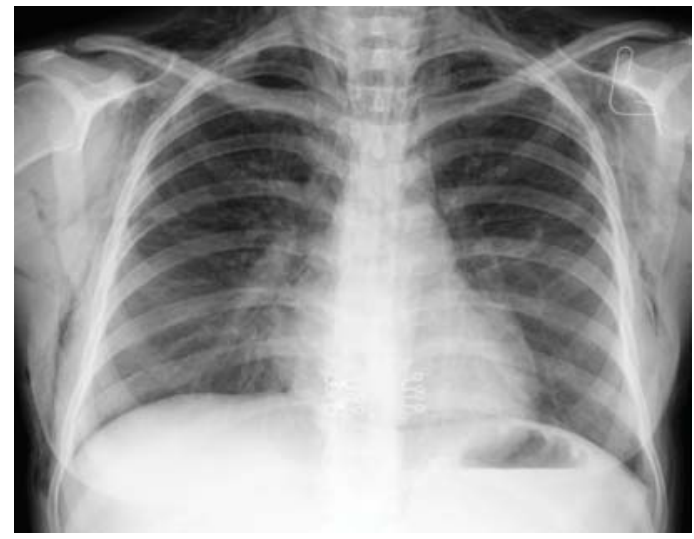

Figure 2. Chest $x$ ray showing subcutaneous epmhysema

On investigation, there were plenty of WBC in the routine urine examination. Routine blood examination, random blood sugar, electrolytes and ECG were normal. Her chest X-ray showed subcutaneous emphysema without pneumothorax (Figure 2). The patient was admitted but the patient left against medical advice on the next day. We tried to contact the patient by telephone. After 10 days, we could contact the patient's husband who said that the patient was doing well and that the swelling had decreased significantly without medication. The patient could not be contacted thereafter.

\section{DISCUSSION}

The onset of symptoms of pregnancy-related pneumomediastinum usually develops during the second stage of labour, but it has been reported during the first stage of labour and during earlier antepartum episodes of coughing, hyperemesis or even spontaneously at rest. ${ }^{4}$ Hamman's syndrome is related to the Valsalva maneuver during the expulsive phase of labour. Possibly, air from ruptured alveoli tracks along the perivascular sheath into the mediastinum. Other reported mechanism include oesohageal rupture during childbirth $^{5}$ or dissection of a pneumoperitoneum. ${ }^{6}$ In our case, the possible cause of subcutaneous emphysema was sudden onset of cough.

The clinical features include chest pain often radiating to the neck and arms. Dyspnea, change in voice, cough, sore throat and tachycardia are also seen. Palpable crepitation over the face, neck and chest is the hallmark of the pneumomediastinum. A fine auscultatory crepitation may be heard synchronous with the heart beat over the left sternal border and is known as Hamman's sign. ${ }^{3}$

Leucocytosis is common and ECG changes include nonspecific ST and T wave abnormalities in $25 \%$ of the patients. Abnormal arterial blood gases have also been reported. ${ }^{7}$ Chest $\mathrm{X}$-ray and CT are diagnostic. Lateral chest $\mathrm{X}$-ray and $\mathrm{CT}$ views are particularly helpful because they improve the visibility of air in the anterior mediastimum. ${ }^{8}$ The differential diagnoses include tension pneumothorax, cardiac tamponade, angina pectoris, pericarditis, dissecting arotic aneurysm, mediastinitis, pulmonary embolism and oesophageal tear. $^{9}$

Signs of cardio respiratory failure are rare and would be present only if pneumopericardium or tension pneumothorax had occurred. Invasive monitoring and aggressive management are required only in such cases $^{7,8}$. The clinical course is often benign, and conservative treatment is preferred because of the negligible risk of perinatal or maternal disability. ${ }^{10}$ Recurrence in subsequent pregnancies is uncommon. ${ }^{11}$ In our patient, the follow-up could not be done as she left hospital against medical advice. 


\section{REFERENCES}

1. Miguil M, Chekairi A. Pneumomediastinum and pneumothorax associated with labour. Int J Obstet Anesth. 2004;13:117-9.

2. Gordon CA. Respiratory emphysema in labor with two new cases and review of 130 cases in the literature. Am J Obstet Gynecol. 1927;14:633-46.

3. Hamman L. Mediastinal emphysema. JAMA. 1945;128:1-6.

4. Heffner JE, Sahn SA. Pleural disease in pregnancy. Clin Chest Med. 1992;13:667-78.

5. Gemer O, Popescu M, Lebowits O, Segal S. Pneumonediastinum in labor. Arch Gynecol Obstet. 1994;225:47-9.

6. Crean PA, Stronge JM, Fitzgerald MX. Spontaneous pneumomediastinum in pregnancy. Br J Obstet Gynaecol. $1981 ; 88: 952-4$.
7. Reeder SR. Subcutaneous emphysema, pneumomediastinum and pneumothorax in labor and delivery. Am J Obstet Gynecol. 1986;154:487-9.

8. Karson EM, Saltzman D, Davis MR. Pneumomediastinum in pregnancy: two case reports and review of the literature, pathophysiology and management. Obstet Gynecol. 1984;64(3):39-43.

9. Hemmadi S, Reid S, Shylasree TS, Lindsay P, Clyburn P. Subcutaneous emphysema with pneumomediastinum in labour. Hosp Med. 2004;65:760.

10. Spellacy WN, Prem KA. Subcutaneous emphysema and pregnancy, report of 3 cases. Obstetrics and Genecology. Oct 1963;22(4):521-3.

11. Hague WM. Mediastinal and subcutaneous emphysema in a pregnant patient with asthma. Br J Obstet Gynaecol. 1980;87:440-3. 